\title{
Influence of the ambient temperature during heat pipe manufacturing on its function and heat transport ability
}

\author{
A. Čaja ${ }^{1 \mathrm{a}}, \mathrm{P} . \mathrm{Nemec}^{1}, \mathrm{M} . \mathrm{Malcho}^{1}$ \\ ${ }^{1}$ Department of power engineering, University of Žilina, Univerzitná 8215/1, Žilina, Slovakia
}

\begin{abstract}
Heat pipe is heat transfer device working at a minimum temperature difference of evaporator and condenser. Operating temperature of the heat pipe determine by properties of the working substance and pressure achieved during production. The contribution is focused on the determining the effect of the initial surrounding temperature where the heat pipe is manufactured and on the obtaining performance characteristics produced heat pipes in dependence of manufacturing temperature. Generally hold, that the boiling point of the working liquid decrease with decreasing ambient pressure. Based on this can be suppose that producing of lower ambient temperature during heat pipe manufacturing, will create the lower pressure, the boiling point of the working fluid will lower too and the heat pipe should be better performance characteristics.
\end{abstract}

\section{Introduction}

Miniaturization of electronic components and increases their performance parameters is also associated with an increase in the thermal power dissipation, which contributes significantly to increasing the operating temperature of these electronic elements, thereby reducing their reliability. With this phenomenon is encountered mainly in power electronics and mechatronics for the design of increasingly complex and energy-consuming equipment. They arise often conflicting requirements for intensification of heat transfer resulting from the trend of reducing these facilities while maintaining the original performance, or even an his increase and levy the necessary heat loss in order to maintain their safe operating temperature. As these devices have less power and are enclosed in a sufficiently large space, the heat dissipation of heat sufficient transport of heat by conduction to the ribbed coolers and radiator fins transfer of free convection in the environment, possibly with forced convection airflow from cooling fans. But when the powerful electronic devices are space-constrained, or if that requirement for minimizing their size, it is a classic method of cooling is sufficient. Therefore, we are finding new ways or intensification of heat transfer. The coolers with heat pipes are currently showing as a progressive cooling system. These devices are structurally and materially to the relatively simple and affordable devices capable of very efficiently dissipate heat in a wide temperature range. Heat pipes are used for cooling equipment with a wide range of cooling performance, from the smallest (of the order of $100 \mathrm{~W}$ ) in computing, to the heat pipes designed for cooling nuclear reactors or smelters performance of the order of $108 \mathrm{~W}$. Material heat pipes and their job descriptions are chosen depending on the environment in which they are to be applied and the desired operating temperature. Heat pipes can be especially useful for heat transfer from a spatially limited places for heat removal from the sealed enclosure, they allow heat flow through the flow of steam and condensate pay in the space in which it is possible to implement the transfer of heat by convection and where effective natural cooling be ensured. Evaporation of the tube resides in thermal contact with a heat source, and the condensation of the heat is discharged frequently ribbed heat transfer surface area. Working fluid in the heat pipe is at operating temperature is in the liquid and in the vapor phase. If the evaporation of the condensation tube is heated and cooled, there is a continuous evaporation of liquid on the inner surface of the evaporation tube, the flow of vapor from the evaporation of the mercury condensation of a vapor to condense on the wall of the condensation. Depending on how it is ensured the return flow of condensate in the tube working fluid, the heat pipe divided into gravity and capillary.

\section{Heat pipe and its properties}

Heat pipe is a device that is used to heat transfer the place with a high temperature place at a lower temperature place. It works on the principle of change the physical state working fluid inside the heat pipe. Operating temperature range is dependent on the used material and used the heat pipe working fluid $[1,2]$. In various experimental measurements it was found that even if the

\footnotetext{
a alexander.caja@fstroj.uniza.sk
} 
heat pipe were made of the same materials and used the same number and types of process materials, nevertheless be the heat pipes had the different transport capabilities.

One possible cause could be a different temperature during filling and exhausting heat pipes. This assumption is confirmed by experimental measurements which were used in three different working materials at three different operating temperatures. As working materials were used water, ethanol and Fluorinert FC72. As the most widely used working fluid is ethanol for their application possible also at temperature below $0{ }^{\circ} \mathrm{C}$. Water compared to ethanol has better thermal capacity. Fluorinert FC72 was used out to determine its characteristics as a working medium. The Fluorinert FC72 is electrically nonconductive substance and its use should be of great importance especially in electrical installations where the risk keeping of electricity in the event of failure of the cooling device, which is undesirable [5].

Table 1. Absolute pressure of working medium at ambient temperature $20^{\circ} \mathrm{C}$.

\begin{tabular}{|c|c|c|}
\hline & $\begin{array}{c}\text { Temperature } \\
{\left[{ }^{\circ} \mathbf{C}\right]}\end{array}$ & $\begin{array}{c}\text { Absolute } \\
\text { pressure [kPa] }\end{array}$ \\
\hline Water & 20 & 2,34 \\
\hline Ethylen & 20 & 7,40 \\
\hline Fluorinert FC72 & 20 & 23,4 \\
\hline
\end{tabular}

\section{Measuring device and measuring values}

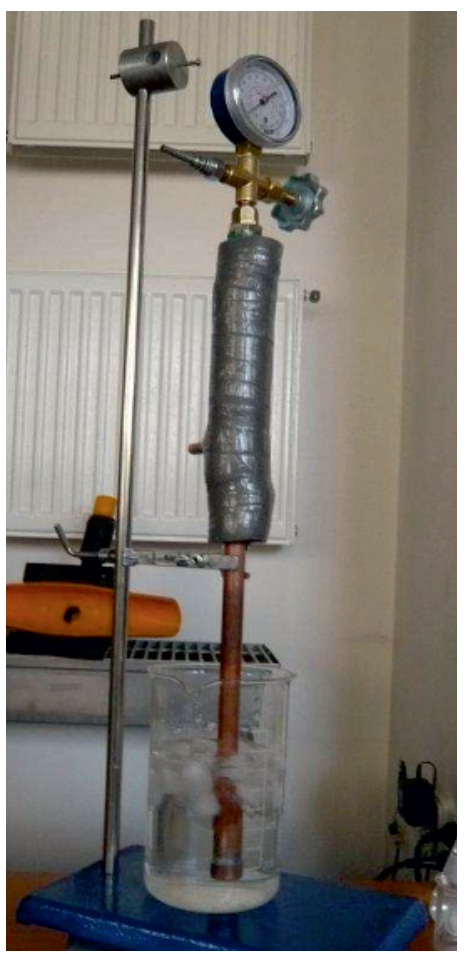

Figure 1. A heat pipe in an ice bath cooled to $0^{\circ} \mathrm{C}$.
Experimental measurement was implemented nine measurements on gravity heat pipe in a vertical position. For heat pipes, were implemented nine measurements with different fillings and performance at different temperatures. The water, ethanol and Fluorinert FC72 were used as working fluids [7]. Working fluids were performed at temperatures of $20^{\circ} \mathrm{C}, 0{ }^{\circ} \mathrm{C},-20^{\circ} \mathrm{C}$. For the calculation of transferred power heat of the heat pipe is used calorimetric method. For the purpose of calculating the transmitted power is determined by the temperature difference of cooling water that flows through the condenser, sensed at the inlet and outlet of the radiator at a given mass flow rate and specific heat capacity of water.

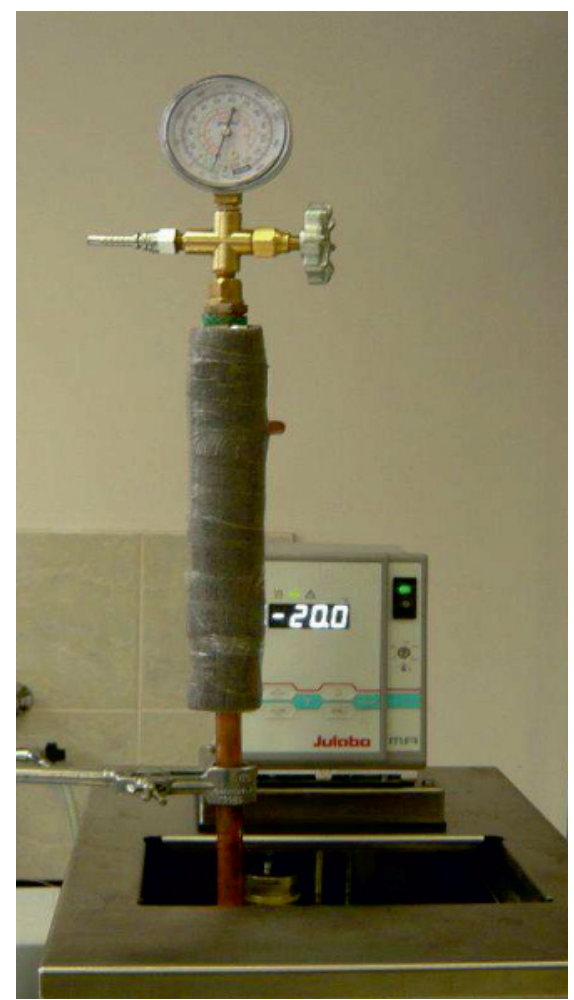

Figure 2. Heat pipe in the thermostat cooled to $-20^{\circ} \mathrm{C}$.

Transmitted thermal output is determined by the relationship [9]:

$$
Q=m \cdot c_{p} \cdot \Delta t
$$

$\mathbf{Q}$ - mean value of power in steady state [W]

m - mass flow rate of cooling water $\left[\mathrm{kg} \mathrm{s}^{-1}\right]$

$\mathbf{c}_{\mathbf{p}}$ - specific heat capacity of water at constant pressure $\left[\mathrm{J} \mathrm{kg}^{-1} \mathrm{~K}^{-1}\right.$ ]

$\Delta \mathbf{t}_{\mathbf{i}}$ - the difference of medium temperature of cooling water in steady state $\left[{ }^{\circ} \mathrm{C}\right]$

The difference of middle temperatures of cooling water is calculated according to the relation:

$$
\Delta t_{i}=t_{v 2}-t_{v 1}
$$

$\Delta \mathbf{t}_{\mathbf{i}}$ - the difference of medium temperature of cooling water in steady state $\left[{ }^{\circ} \mathrm{C}\right]$ 
$\mathbf{t}_{\mathrm{v} 2}$ - the value of the outlet temperature of cooling water $\left[{ }^{\circ} \mathrm{C}\right]$

$\mathbf{t}_{\mathbf{v} 1}$ - The value of the inlet temperature of cooling water $\left[{ }^{\circ} \mathrm{C}\right]$

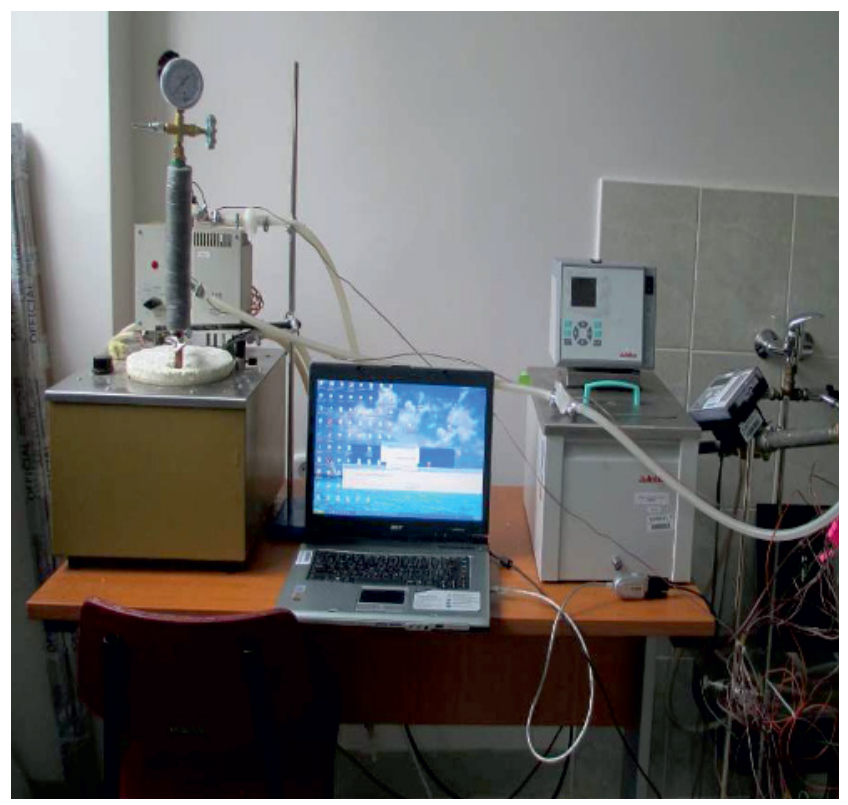

Figure 3. Measuring state for measurement thermal performance transferred by heat pipe.

The condensation part of the total heat pipe was supplied output of about $550 \mathrm{~W}$ and the temperature of heating medium to be maintained at the $80{ }^{\circ} \mathrm{C}$. Given that, as a heat source was used older type thermostat, where the desired water temperature has been corrected manually, there were increased fluctuations temperature and therefore the thermal power transmitted, which is also shown in figure 3 . On the condensation part was mounted water cooler, which makes it possible to relatively accurately measure the size of heat removal . Inlet and outlet coolant in the radiator was placed thermocouples to determine the temperature difference needed for the calculation. Quantity having passed the coolant was scanned ultrasonic flow KAMSTRUP. Complete assembly of experimental equipment is shown in figure 3. On the basis of the measurements were constructed graphs of temperatures depending on the type of tube and the conditions during the manufacture of tubes themselves.

Of readings and graphs show that the filling temperature of $20{ }^{\circ} \mathrm{C}$, as expected, was the best working substance with water -borne power of about $375 \mathrm{~W}$. As a second working fluid in order ethyl alcohol was a power about $300 \mathrm{~W}$ and the last working fluid Fluorinert FC72 is the transmitted power of about $230 \mathrm{~W}$. An ambient temperature of $0{ }^{\circ} \mathrm{C}$ was again best medium is water, but the difference between the remaining two substances were much smaller, approximately $50 \mathrm{~W}$. The worst working medium with transmitted power less than $100 \mathrm{~W}$ was water that was frozen and evaporation of the heat pipe was blowing air over chilled to $-20{ }^{\circ} \mathrm{C}$. Best working substance was contrary ethyl transmitted power of about 240W and soon followed with Fluorinert FC72 transmitted power of about $200 \mathrm{~W}$.

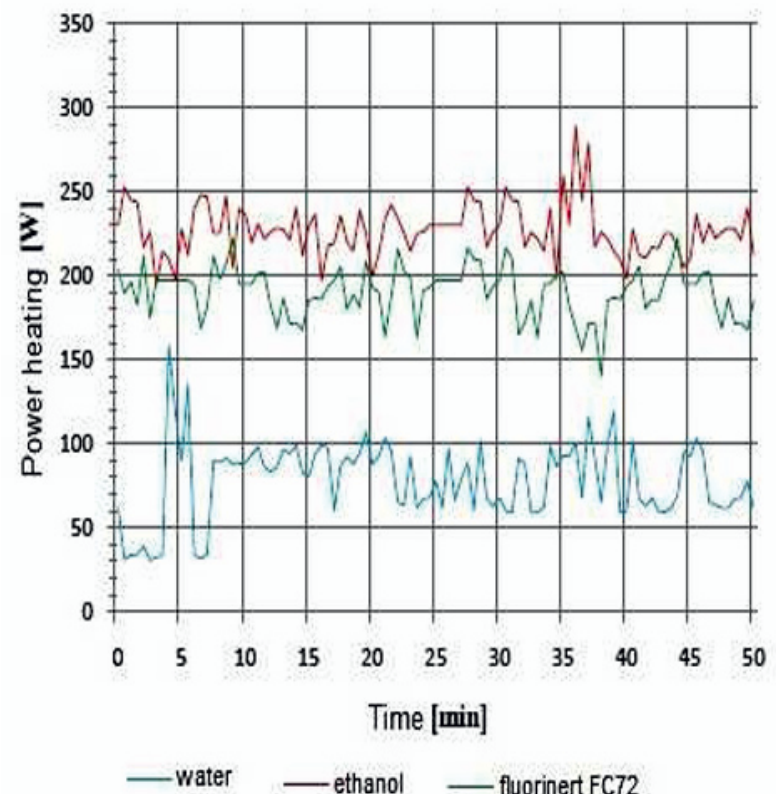

Figure 4. Graph showing the progress of transferred performance each heat pipes made at an ambient temperature of $0{ }^{\circ} \mathrm{C}$.

\section{Conclusions}

Based on the experimental measurements it is possible to say that the effect of ambient temperature has a significant influence on the transport properties of heat pipes. The most significant the difference was observed for heat pipes with working medium water. At temperature of $-20{ }^{\circ} \mathrm{C}$, the working fluid of the heat pipe in a solid state and, therefore, be it negative pressure as great influence, as in a liquid. However, the value of absolute pressure at this temperature and a temperature of $20{ }^{\circ} \mathrm{C}$ is different, which results in operating temperature the difference and hence the thermal power transported by the heat pipes.

Given the above, it creates room for further investigation of these dependencies. To reduce fluctuations in temperature would be appropriate to replace the thermostat with manual corrected for temperature sensing thermostat with automatic temperature and corrected. This would avoid the impact of human error and minimize the impact of inertia radiator. Taking simply the heat pipes and the use thereof, it is obvious that the tube filled with water, even if they have better transport properties such as ethanol, are not suitable for application in the external environment in our geographic area. So far, yet most widely used working fluid in the heat pipe for common applications up to $120{ }^{\circ} \mathrm{C}$ ethanol. It is a substance that can be used in temperatures below freezing; it is sufficiently low pour point. Operating temperature range is set vacuum achieved in the production of heat pipe. Thereby achieving greater depression, the sooner will 
heat pipe work. At least we have yet to experience with Fluorinert FC72. Has a similar property of compounds such as ethanol, in addition, the electrically nonconductive. It is therefore assumed its use in electrical engineering using the right type of heat pipes.

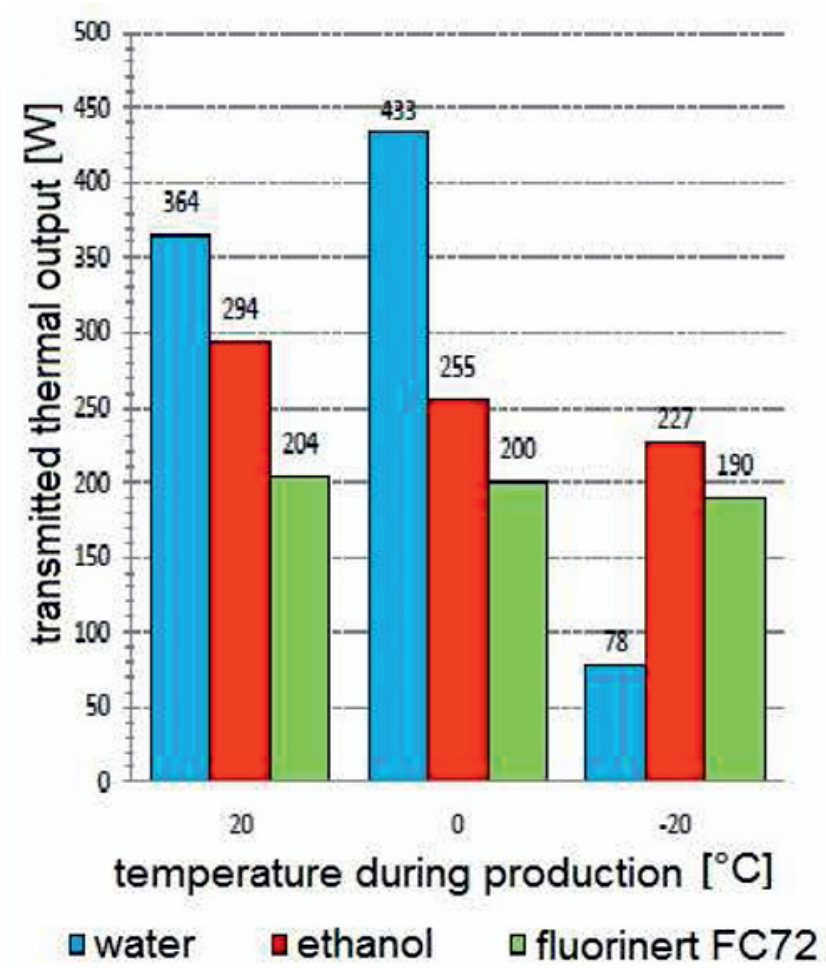

Figure 5. Comparison of heat performance transferred by individual heat pipes.

\section{Acknowledgment}

This work was part of the project KEGA-064ŽU$4 / 2012$

\section{References}

1. Ochterbeck, Jay M., Heat Transfer Handbook, 1. Edition.M. Ben Rabha, M.F. Boujmil, M. Saadoun, B. Bessaïs, Eur. Phys. J. Appl. Phys. (to be published)

2. Gaugler, R. S.: Heat transfer devices, U.S. patent 2,350,348 1944 .

3. Trefethen, L.: GE Tech. Int. Ser. No G15-D114, General Electric Co., NY 1962

4. Grover, G. M., Cotter, T.P. Erikson, G.F.: Structures of very high thermal conductance, J. Appl. Phys. (1964)

5. Nemec, P., Jandačka, J., Malcho, M., ERIN 201394 (2013)

6. Kapjor, A., Kosecová, A., Papučík, Š., TRANSCOM 69-72 (2005)
7. Hužvár, J., Jandačka, J., Oksanen, A. Optimization using exergy-based methods and computational fluid, 219-224 (2009)

8. Lenhard, R. Power control and optimization, (2010)

9. Kolkovám A., Smitka, M., Malcho, M., Transcom 2013, 269-272 (2013)

10. Pilát, P., Mičicová, J. TRANSCOM 2009, 117-119 (2009)

11. Jandačka, J., Nosek, R., Papučík, Š. Vykurovanie 9598 (2011)

12. M. Malcho, S. Gavlas, R. Lenhard, Acta metallurgica slovaca conference. Vol. 2, no. 1, 132-137 (2011)

13. F. De Lillo, F. Cecconi, G. Lacorata, A. Vulpiani, EPL, 84 (2008) 